\title{
Psicologia Ambiental: múltiplos olhares sobre as relações pessoa-ambiente
} Environmental Psychology: multiple perspectives on
person-environment interactions

http://dx.doi.org/10.5007/2178-4582.2013v47n1p172

Camila Klein

Universidade do Oeste de Santa Catarina, Joaçaba/SC, Brasil

\section{Resenha de:}

CAVAlCANTE, S.; ELALI, G.A. (org.). Temas Básicos em Psicologia Ambiental. Petrópolis: Vozes, 2011, 318p.

O livro Temas Básicos em Psicologia Ambiental, organizado pelas Professoras Dras. Sylvia Cavalcante (UNIFOR) e Gleice A. Elali (UFRN), materializa os esforços dos professores e pesquisadores que integram o Grupo de Trabalho em Psicologia Ambiental da Associação Nacional de Pesquisa e Pós-graduação em Psicologia (GT-Psi-Ambiental/ANPEPP). O grupo busca fortalecer e incentivar a produção e publicação bibliográfica na área, sobretudo em língua portuguesa.

A obra reúne, sob a ótica da Psicologia Ambiental (PA), 25 textos que podem ser subdivididos em três grandes categorias: 1) temas amplos e não exclusivos da PA; 2) temas trabalhados pelas ciências humanas e sociais e 3) temas que têm origem na própria PA.

A primeira categoria de textos trata de temas mais amplos sobre ambiente. Mara Ignez Campos-de-Carvalho (USP-RP), Sylvia Cavalcante e Lana Mara Andrade Nóbrega (UNIFOR/UNESP), no capítulo Ambiente, discorrem sobre o conceito desde suas múltiplas conotações na sociedade até o entendimento que a PA tem sobre o tema. As autoras utilizam-se da perspectiva sistêmica para aprofundar a discussão, e evidenciam uma compreensão ecológica das relações pessoa-ambiente. Beatriz Fedrizzi (UFRGS) contribui para o capítulo sobre Biofilia e Biofobia. Os termos representam, respectivamente, as recompensas/ efeitos positivos da natureza e a noção de perigo. A autora discute, sob o ponto de vista evolucionário, os conceitos e pesquisas na área, especialmente em biofobia. Ariane Kuhnen (UFSC), no texto sobre Desenvolvimento Sustentável, tece considerações sobre a função política deste conceito, já que ele baliza políticas públicas que buscam equilibrar crescimento econômico e conservação do meio-ambiente. A autora também apresenta o noção de ecodesenvolvimento, e encerra o capítulo com breve contribuição sobre psicologia da sustentabilidade.

Ainda no grupo de textos amplos sobre ambiente, Camila Bolzan de Campos (SENAC-RS) descreve a Gestão Ambiental como uma prática empresarial 
que integra os princípios do desenvolvimento sustentável à filosofia e à prática das organizações. O capítulo dá um abreviado panorama das ferramentas de gestão ambiental disponíveis e finaliza com uma reflexão acerca da aplicabilidade da PA na implantação/implementação da gestão ambiental. Gleice Azambuja Elali e Marília Luiza Peluso (UnB) discorrem sobre Interdisciplinariedade, conceituam, posicionam historicamente e evidenciam sua importância para a PA, que utiliza esta abordagem como uma estratégia para agregar múltiplos enfoques de várias disciplinas como biologia, ecologia, geografia dentre outras.

A estratégia de uso de múltiplos métodos na coleta e análise de dados é apresentada por Harmut Günther (UnB), Gleice Azambuja Elali e José Q. Pinheiro (UFRN), no capítulo Multimétodos. Este minimiza os vieses que são próprios às pesquisas nas quais se adota um único procedimento de pesquisa. Os autores destacam a importância da abordagem "multimétodo", "triangulação metodológica" ou "mixed methods", dada a complexidade das relações pessoa-ambiente, e a própria natureza da PA enquanto "conjunto heterogêneo" de áreas de estudo. Zenith Nara Costa Delabrida (UnB/UFS) fala sobre Pesquisa-ação e encerra a categoria de textos mais abrangentes sobre ambiente. O capítulo, a partir da concepção lewiniana, conceitua e discute sua aplicabilidade, aproveitando para diferenciar a pesquisa-ação da pesquisa convencional e da pesquisa participativa. A autora considera a importância das pesquisas tanto qualitativas quanto quantitativas, e a relevância da pesquisa-ação enquanto abordagem que busca soluções de problemas não só teóricos, como também práticos.

No segundo agrupamento de textos, as organizadoras destacam a significativa contribuição da PA em temas desenvolvidos pelas ciências humanas e sociais, como geografia, arquitetura e urbanismo e educação ambiental. No capítulo Apropriação, que trata da formação de "lugares" pelo ser humano, Sylvia Cavalcante e Terezinha Façanha Elias (UNIFOR) discorrem sobre a noção sociológica de apropriação e situam historicamente o uso do conceito pela psicologia e como ele se manifesta. Maria Ignês Gasparetto Higuchi (INPA/UFAM), Ariane Kuhnen e Zulmira Áurea Cruz Bomfim (UFC) tratam do tema Cognição Ambiental descrevendo-o como "conhecimento apreendido, armazenado e reelaborado sobre o ambiente físico". As autoras expõem os aspectos constitutivos do conhecimento espacial sob a ótica piagetiana, e finalizam apontando os mapas mentais (ou mapas cognitivos) como um dos recursos de avaliação da cognição ambiental.

O capítulo Espaço e Lugar é desenvolvido por Sylvia Cavalcante e Lana Mara Andrade Nóbrega, que definem e diferenciam os dois termos, e discorrem sobre a formação de lugar a partir da relação das pessoas com o espaço. Ada Raquel Teixeira Mourão (UB/UFPI) contribui para dois capítulos: Identidade de Lugar e Identidade Social Urbana. No primeiro, conta com a parceria de Sylvia Cavalcante e no segundo com Zulmira Áurea Cruz Bomfim. As autoras definem os aspectos de cada conceito, suas dimensões e como se manifestam. Os dois temas entrelaçam-se na medida em que a identidade social 
urbana "pode ser considerada uma extensão da identidade de lugar especificamente relacionada ao ambiente urbano".

No texto Valores Ecológicos, Claudia Marcia Lyra Pato (UnB) os descreve como um sistema de referências que influencia o comportamento ecológico na busca do equilíbrio entre os diversos ecossistemas. A autora apresenta a importância de S.H.Schwartz com seu modelo teórico de valores humanos, e a contribuição de P.C.Stern com a teoria do ambientalismo. Completando o segundo agrupamento de temas, Ariane Kuhnen fala sobre Percepção Ambiental, que constitui-se a partir das experiências físicas da pessoa com seu entorno, e envolve aspectos psicossociais, socioculturais e históricos. O capítulo aponta vários estudos na área e encerra com uma discussão acerca do processo de construção da percepção ambiental.

A terceira categoria de textos compreende tópicos que têm origem na própria PA. O capítulo Affordance, de Harmut Günther, trata do impacto do ambiente sobre o comportamento humano, e analisa este fenômeno sob dois olhares: a valência da teoria de campo de Kurt Lewin e o conceito affordance de James J. Gibson. A pesquisadora Suzana M. Alves (ECA-UK) trabalha o tema Ambientes Restauradores, que compreende os espaços que proporcionam experiências de restauração da atenção e consequente redução da fadiga mental. Destaca seis linhas de pesquisa sobre o tema, seus avanços e lacunas, bem como trata de importantes conceitos correlacionados: atenção direcionada e fadiga mental.

Gleice Azambuja Elali e Samia Thaís Feijó de Medeiros (UFRN) contribuem para o capítulo Apego ao Lugar (Vínculo com o lugar - Place Attachment). $\mathrm{O}$ conceito diz respeito à relação afetiva com o lugar, levando em consideração as características físico-espaciais do local e as vinculações simbólico-afetivas próprias das relações pessoa-ambiente. O texto também trata das três dimensões de apego ao lugar: funcional, simbólica e relacional.

Em Arranjo Espacial, Mara Ignez Campos-de-Carvalho destaca a forma como móveis e equipamentos estão distribuídos em um local, fornecendo mensagens diretas e simbólicas que podem promover ou inibir certas práticas interativas. Neste capítulo a autora dá ênfase à aplicação do conceito no contexto educacional infantil. Mais uma vez, José Q. Pinheiro dá sua contribuição e fala sobre Behavior Setting, a partir dos estudos de Roger Barker. Unidade básica da psicologia ecológica, o conceito de behavior setting expressa a relação de interdependência entre comportamento e ambiente, compreendendo um conjunto de padrões estáveis de comportamento, com limites espaciais e temporais específicos.

Fernanda Fernandes Gurgel (UnP/ FACEX) e José Q. Pinheiro discutem Compromisso Pró-ecológico. Os autores defendem o emprego do termo "compromisso", que denota a relação cognitivo/afetiva de caráter positivo com o meio ambiente. Também discutem a utilização do termo em áreas correlatas, os instrumentos para avaliação do compromisso pró-ecológico e as limitações e divergências que a teorização do conceito ainda apresenta.

O Comportamento Ecológico é debatido por Claudia Marcia Lyra Pato e Camila Bolzan de Campos, e pode ser definido como um conjunto de ações 
intencionais ou não, que resultam em proteção do meio ambiente. O tópico expõe alguns estudos empíricos que investigam o conceito e aponta as avaliações de comportamento ecológico disponíveis na literatura. José Q. Pinheiro e Gleice Azambuja Elali, no capítulo Comportamento Sócio-espacial Humano, discutem a importância e influência da dimensão espacial nas relações humanas. Elucidam os conceitos de aglomeração e privacidade, e a correlação entre dimensão espacial, ordem social, status e poder. O conceito integra o processo de comunicação interpessoal e é um dos "mediadores da interação pessoa/ ambiente".

Ainda na última categoria de textos, Isolda de Araújo Günther e Thais Branquinho de Oliveira Fragelli (UnB) definem Estresse Ambiental como uma série de reações individuais frente à situações ambientais adversas, na tentativa de recobrar o estado de equilíbrio. Também exemplificam a correlação entre estresse/saúde e estresse/organização do espaço. No tema Pressão Ambiental (Environmental Press), também de Isolda de Araújo Günther, a abordagem se dá a partir das contribuições do Modelo Ecológico de Envelhecimento de Lawton e Nahemow. O termo é definido como uma demanda do ambiente que afeta o bem-estar do indivíduo, na medida em que exige competências específicas para a adaptação.

Completando os assuntos que têm origem na PA, José Q. Pinheiro e Fernanda Fernandes Gurgel falam sobre Perspectiva Temporal. O texto é debatido a partir de duas formulações teóricas que contribuem na compreensão e estudo da dinâmica pessoa-ambiente-tempo: o Inventário Zimbardo de Perspectiva Temporal, de Philip Zimbardo, e a Escala de Consideração de Consequências Futuras, de Alan Strathman.

Dessa forma, a obra propõe uma discussão inicial para cada um dos 25 temas selecionados e reflete a diversidade de abordagens e metodologias entre autores e vertentes de pesquisa em Psicologia Ambiental. O livro também pode ser utilizado como um guia-rápido, rico em referências bibliográficas relacionadas a cada conceito. Leitura imprescindível para aqueles que procuram ter contato inicial com a temática e aqueles que desejam ampliar seus conhecimentos e pesquisas no campo das relações pessoa-ambiente.

Recebido em: 23/05/2013

Aceite em: 25/07/2013

Camila Klein possui graduação em Psicologia pela UFSC, especialização em Comportamento Humano nas Organizações pela Universidade do Oeste de Santa Catarina - UNOESC. Mestranda em Psicologia na UFSC. Endereço para correspondência: Rua Percy João de Borba, 220. Trindade. Florianópolis/SC, Brasil. CEP 88036-200 E-mail: kleincamila.ck@gmail.com 